\title{
Extensional Article \\ Assessment of the structure of the nematode community as an index for soil health
}

Farnaz Fekrat, Reza Ghaderi ${ }^{凶}$

Department of Plant Protection, Shiraz University, Shiraz, Iran

Received: 03.10.2020 Accepted: 08.30.2020

Fekrat F, Ghaderi R (2020) Assessment of the structure of the nematode community as an index for soil health. Plant Pathology Science 9(2):129-136. DOI: 10.2982/PPS.9.2.129.

\section{Abstract}

By studying the structure of the nematode community, healthy and unhealthy soils can be identified in terms of biodiversity and nutrient network. This information is useful for managing soil nutrient networks. The study of the nematode population structure as a biological indicator of soil health is based on the assessment of biodiversity indices, nutrition groups, population dynamics, soil nutrient network profile, biomass and metabolic profile. Practical applications for studying the structure of nematode populations in agricultural and natural ecosystems are described.

Key words: Feeding groups, Metabolic footprint, Soil food web profile

$$
\begin{aligned}
& \text { مقاله ترويجى } \\
& \text { ارزيابى ساختار جامعه نماتدها به عنوان شاخصى براى سلامت خاكى } \\
& \text { فرناز فكرت، رضا قادرى } \\
& \text { گروه گياهيزشكى، دانشكده كشاورزى، دانشعاه شيراز، شيراز }
\end{aligned}
$$

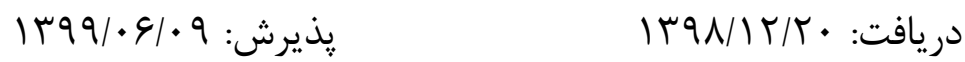

$$
\begin{aligned}
& \text { فكرت ف، قادرى ر (99 ( ) ارزيابى ساختار جامعه نماتدها به عنوان شاخصى براى سلامت خاك. دانش }
\end{aligned}
$$

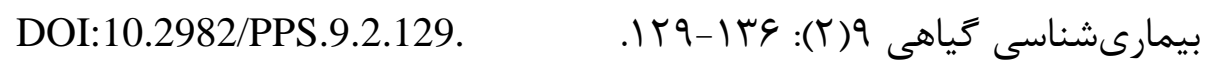

$$
\begin{aligned}
& \text { جكيده } \\
& \text { وازگكان كليدى: يروفيل شبكه غذايى خاك، گروههاى تغذيه، نغاره متابوليك }
\end{aligned}
$$

Corresponding author: rghaderi@shirazu.ac.ir 
دخالت بشر در محيط زيست و انواع مشكلات ناشى از آن، در دراز مدت بر سلامت خاك اثر كذاشته است. ارزيابى اين تغييرات گاه توسط اندازهيرى شاخصهاى فيزيكى و شيميايى امكانيذير نيست بلكه لازم است از شاخصهاى زيستى استفاده كرد. شاخصهاى زيستى (شناساكرهاى زيستى)، موجودات زندهاى هستند كه به سرعت تحت تأثير تغييرات قرار كرفته و وضعيت سلامت يك زيستبوم را نشان مى دهند (Angst et al. 2017, Tolfa et al. 2017). آنها يك يا گروهى از گونههاى موجودات زنده هستند كه عملكرد، فراوانى، تنوع يا وضعيت فيزيولوزيكىشان بيانكر شرايط زيستبوم است (1981 Karr ) كرفت (Bongers 1990, Yeates et al. 1993, Bongers and Bongers 1998). فراوانى و حضور همهجايى نماتدها آنها را به بزرگترين نشانكرهاى پايش آلودگى هاى زيست محيطى تبديل كرده است (Yeates et al. 2009). نماتدها به دليل داشتن راهبردهاى توليدمثل محافظه كارانه، به صورت ذاتى جمعيت ڤֶايدارى دارند، بنابراين تغييرات مشاهده شده در ساختار جامعه نماتدها ( Nematode Trett et ( را تا حد زيادى مىتوان به اثرهاى تغيير شرايط محيطى نسبت داد (community structure al. 2009 نماتدها قادر به دور شدن از شرايط تنش نيستند و به دليل داشتن كوتيكول نفوذيذير و تماس نزديك با آب درون خاك، سريعتر از بقيه موجودات در معرض آلايندههاى محيطى قرار مى گيرند. كروههاى مختلف نماتدها به اختلالها و دستورزى محيط زيست ياسخهايى متفاوت نشان مىدهند (Bongers and Ferris 1999). نماتدها عادتهاى تغذيهاى متفاوتى دارند كه به آسانى از روى تغييرات دستخاه گوارش آنها قابل تشخيص است (Ferris and Bongers 2009, Yeates et al. 2009).

\section{كاربرد نماتدها براى محاسبه شاخصهاى تنوع زيستبوم}

براى توصيف ساختار جوامع نماتدها از شاخصهاى تنوع آرايههاى نماتد (كونه، جنس يا خانواده) استفاده مىشود. مهرمترين آنها شاخصهاى غناى گونهاى (Species richness)، تنوع گونهاى (Species diversity) نيز براى محاسبه تنوع نماتدها در يك زيستبوم ارائه شده است ( Neher and Darby 2009, Ferris

\section{كاربرد نماتدها براى برآورد شاخصهاى عملكرد زيستبوم}

شاخصهاى تنوع ناهمگًنى موجودات زنده در يك زيستبوم را نشان مىدهند، اما اطلاعاتى درباره عملكرد (Function) و خدمات (Services) يك زيستبوم ارائه نمى دهند. نخستين شاخصهاى عملكرد 
زيستبوم بر اساس عادتهاى مختلف تغذيه در نماتدها تعيين كرديد (Yeates et al. 1993). پس از آن راهبردهاى ديناميك جمعيت، يعنى گروههاى Colonizer-persister) c-p مورد توجه قرار گرفت

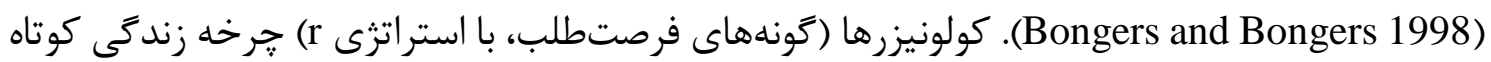

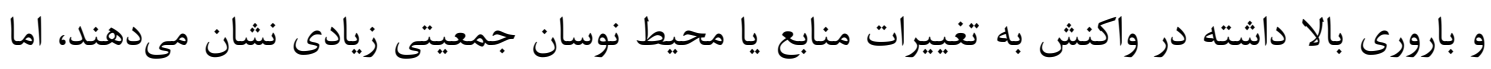
يرسيسترها (كونهاى داراى قدرت رقابت، با استراتزى K) جرخه زندگى طولانىتر و بارورى كمتر داشته

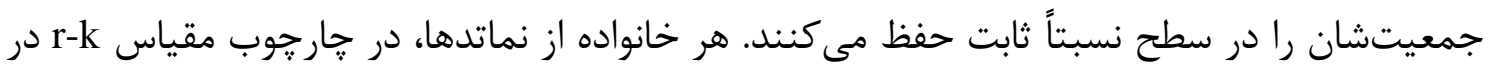
يكى از ينج گَروه c-p قرار مى گيرد كه با افزايش درجه، حساسيت نماتد به تغيير شرايط محيطى بيشتر مىشود (Bongers 1990, Bongers and Bongers 1998, Ferris and Bongers 2009). تلفيق عادتهاى تغذيه نماتد با كروههاى c-p منجر به ارائه كروههاى كاركردى (functional guilds كرديد و سيس شاخصهاى گروه maturity index family) MI اطلاعات جامعترى درباره عملكرد زيستبومها ارائه دادند ( Bongers and Bongers 1998, Ferris et al. 2001, Ferris and Bongers 2009, Ferris

شاخص كم MI (جمعيت تمام نماتدها به غير از نماتدهاى انگل كياهى) بيانكر محيط برهم خورده (مثل عمليات خاكورزى) و يا غنى شده (مثل اضافه شدن نهادهاى كشاورزى از قبيل كود و سم) است و

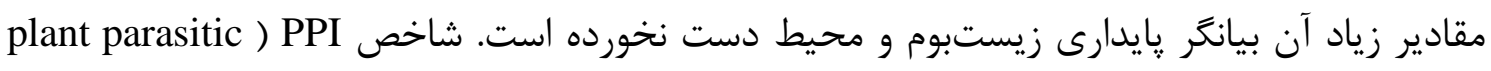
مشابه MI (index

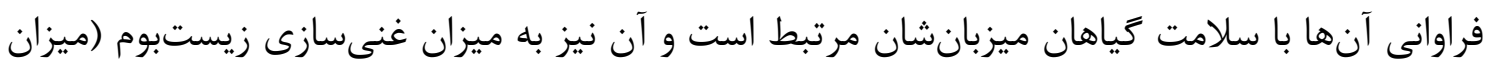

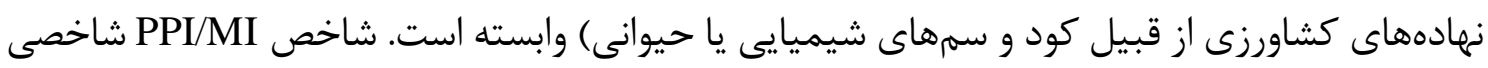

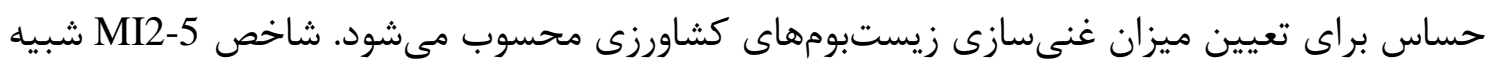

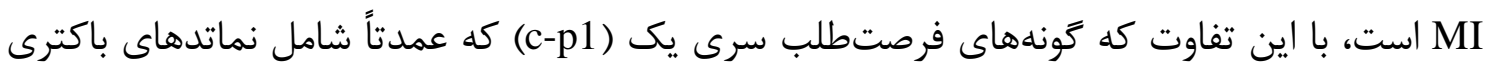
خوار زيرراسته Rhabditina هستند، حذف مىشوند. شاخص SMI شاخص ديخرى از خانواده MI براى تمام نماتدهاى سيستم، شامل انكلهاى گياهى، بر اساس اين ادعا است كه كل جامعه اطلاعات كاملى

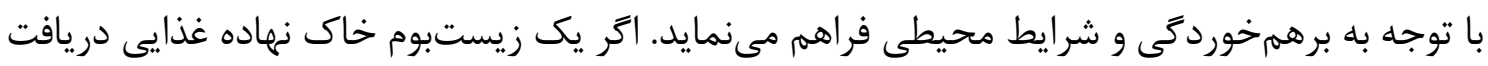

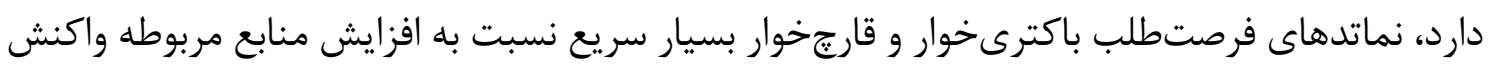

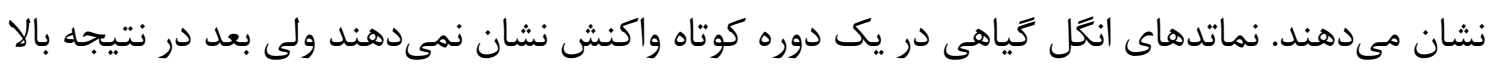

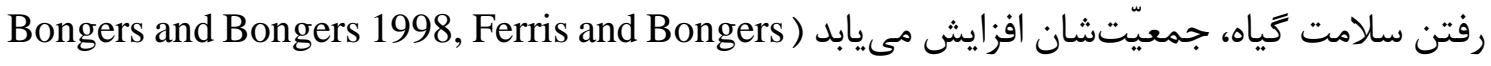
.(2009, Ferris 2012 


\section{شاخصهاى تكميلى عملكرد زيستبوم}

فريس و همكاران (Ferris et al. 2001, 2004) مفاهيم شاخصهاى عملكرد را با تعريف شاخصهاى Structure index, (Enrichment index, EI) داخرى از جمله شاخص غنىسازى ساختار SI )، شاخص یايه (Basal index, BI) و شاخص كانال (Chanel index, CI) اصلاح كردند تا بر اساس ساختار جامعه نماتدها ديدكاه جامعترى در زمينه عملكرد زيستبوم به دست آيد. اين محققان، نماتدهاى فرصتطلب عمومى گروه c-p2 (فون زايه) را نماينده گروهى دانستند كه با حضور دائم و مقاوم در اكثر شبكههاى غذايى خاك، قادر به زنده ماندن حتى در بدترين شرايط هستند. دو محور از اين حالت يايه نماتد بيرون مى آيد، يكى شاخص غنىسازى (EI) را تعريف مى كند كه حاكى از فراوانى وزنى نماتدهاى باكترىخوار c-p1 و قارجخوار c-p2 است و ديخرى شاخص ساختار (SI) است كه از نسبت وزنى نماتدهاى كروههاى c-p3-5 به كروههاى c-p2-5 به دست مى آيد. شاخص يايه (BI)، نسبت وزنى نماتدهاى c-p2 به كل نماتدهاى موجود مىباشد. وضوح بيشتر در مورد شاخص غنىسازى توسط شاخص كانال (CI) ارائه شده است كه نشان دهنده جريان نسبى منابع در داخل شبكه غذايى از طريق مسيرهاى تجزيه به واسطه قارجها و باكترىها است (Ruess and Ferris 2004). فرمولهاى محاسبه اين شاخصها در برخى منابع (Ferris et al. 2001, Ferris and Bongers 2009, Ferris 2013 ارائه شده است و همجنين از طريق نرمافزار آنلاين NINJA و با باركذارى فايل حاوى فهرست آرايههاى نماتد قابل برآورد است (Sieriebriennikov et al. 2014).

\section{يروفيل شبكه غذايى خاك}

يروفيل شبكه غذايى خاى (Soil food web profile) به عنوان قالبى براى توسعه شاخصهاى فوق ارائه كرديد (Ferris et al. 2001). اين يروفيل بر دو محور اصلى يعنى شاخص غنىسازى (EI)) و شاخص ساختار (SI) استوار است. بر اساس اين شاخصها هر زيستبوم در يكى از جهار قسمت يروفيل قرار مى گيرد. خاكهاى قسمت A Q داراى كانال تجزيه باكتريايى و شبكه غذايى برهمخورده با تركيباتى با نسبت كربن به ازت يايين غنىشدهاند. هستند خاكهاى قسمت B داراى شبكه غذايى در حال تكامل با تركيبات حاوى مقادير يايين كربن به ازت غنى شدهاند و فرآيند تجزيه از كانالهاى باكتريايى صورت مى گيرد. خاكهاى قسمت C داراى شبكه غذايى ساختاريافته هستند، نسبت كربن به ازت در آنها متوسط تا بالا است و تجزيه توسط قارجها و باكترىها و به صورت متعادل انجام مىشود. خاكهاى قسمت D داراى شبكه غذايى تخريب شده هستند، از نظر عناصر غذايى فقير هستند و تجزيه

عمدتاً از طريق قارجها است (Ferris et al. 2001, 2004). 


\section{زيست توده و نكاره متابوليك نماتدها}

در حالى كه شاخصهاى تنوع و عملكرد، ابزارهاى توصيفى مفيدى براى ارزيابى شبكه غذايى و شرايط زيستبوم هستند، اما اطلاعات كاملى در مورد ميزان فعاليت شبكه غذايى زيستبوم ارائه نمى دهند. به عنوان مثال، جوامع مختلف با تعداد زياد يا كم نماتد ممكن است داراى شاخصهاى تنوع، MI، غنى سازى و ساختار يكسان باشند. با ايجاد شاخصهاى ساختار و عملكرد شبكه غذايى و جمعآورى اطلاعات در مورد زيستشناسى و رفتار نماتدها، ارزش مطالعه زيست توده (Biomass) و متابوليسم در بومشناسى بيشتر از يیش شده است. در حقيقت، براى عملكرد يك زيست بوم، فرآيندهاى مختلف مانند برگشت غذا، كربن، نيتروثن و فسفر به خاك توسط موجودات زنده درون خاى (از جمله نماتدها)، ضرورى هستند كه هر كدام در جذب كربن در شبكه غذايى و جريان انرزى درون خاك سهمى دارند، لذا كربن و انرزى منابعى هستند كه اندازه و فعاليت شبكه غذايى را تعيين مى كنند. جهت تعيين سهم نماتدها در اين مقوله مىتوان از دادههاى ريختسنجى نماتدها، شاخصهاى بسيار مفيدى همجون زيست توده و ميزان كربن مصرفى توسط نماتدها را محاسبه نمود (Ferris 2010, Van den Hoogen et al. 2019). نعاره متابوليك (Metabolic footprint) ابزار ارزشمندى است كه اطلاعات بيشترى را درباره كيفيت خاى و عملكرد يك زيستبوم ارائه مىدهد (Ferris 2010). هر نغاره متابوليك يك محور توليد و يك محور تنفس (Respiration component) دارد. محور توليد بيانكر (production component) ميزان كربن مصرف شده طى فرآيند رشد و توليد تخم است و با اندازه نماتد همبستكى مثبت دارد. محور تنفس ميزان كربن مصرفى در فعاليت متابوليكى نماتد را برآورد مى كند (Ferris 2010, 2013). لذا نغاره متابوليك، محاسبه مجموع اجزاى توليد و تنفس براى آرايههاى نماتدى است. نغاره متابوليك ميك غنىسازى (Enrichment footprint) مرتبط به آن دسته از نماتدهايى است كه بيشترين سرعت ياسخ گَيى به غنى سازى زيستبوم را دارند در حالى كه نغاره متابوليك ساختارى (structure footprint) مربوط به سطوح بالاى تغذيهاى نماتدهاست كه نقش تنظيمى در شبكه غذايى دارند. براى تعيين نغاره عملكردى (Functional footprint) يك زيستبوم، بايستى نغاره متابوليك غنىسازى و ساختارى نماتد را در يك محيط محاسبه كرد.

\section{كاربردهاى عملى مطالعه ساختار جامعه نماتدها}

اغلب اقدامهاى كشاورزان كه سعى در بهبود عملكرد محصول دارند به طور ناخواسته در دراز مدت منجر به كاهش فوايد و خدمات يك زيستبوم كشاورزى مى يك زيستبوم كشاورزى با زيستبوم طبيعى مجاور مقايسه مىشود، مشخص مى گردد كه دخالت بشر Sánchez-) در زيستبوم خاك مىتواند به شدت بر فراوانى و تنوع جامعه نماتدها در خاك اثر بحذارد 
(Moreno and Navas 2007 يكى از شايعترين اثرهاى تخريبى در زيست بومهاى كشاورزى، كشت مكرر در خاك است (McSorley et al. 2008). ميزان تنوع زيستى با كشت زمين، اضافه كردن مقادير بالاى آفت كشها و كودها، انجام عمليات خاكورزى، جمع آورى بقاياى گياهى، اسيدى شدن خاك و آلودگى به عناصر سنگين كاهش مىيابد (Neher 2001, Navas et al. 2010). قرار دادن نماتدها در كروههاى c-p براى پيشبينى حساسيت آرايهها به عوامل تنشززا مفيد است. به عنوان مثال زندهمانى گروههاى c-p بالا در خاى در اثر كاربرد تركيبات شيميايى از جمله كودهاى شيميايى نيتروزنه كاهش ميىيابد. يزوهشهاى اخير نشان (Sohlenius 1990, Yeates 1997, Zhang et al. 2019) مى دهد كه حتى گرم شدن آب و هوا و در نتيجه خشكى لايههاى خاك، جامعه نماتدهاى خاك را در يك زيست كاه تغيير مىدهد (Ma et al. 2018).

\section{نتيجه}

استفاده از نماتدها در نقش شاخصهاى زيستى، با ادغام طبقهبندى رفتارهاى تغذيهاى نماتدها با ويزگى هاى زيستى، يُيشرفت قابل ملاحظهاى داشته است و به نظر مىرسد با بيشرفت روشهاى مولكولى و قدرتمندتر شدن رهيافتهاى آمارى، ارزيابى ساختار جمعيت نماتدها نقش :ررنخترى را به عنوان شاخصهاى زيستى در خاكهاى مختلف دارد ـ در حال حاضر با مطالعه ساختار جامعه نماتدها مىتوان خاكهاى سالم و ناسالم را از نظر تنوع زيستى و شبكه غذايى تشخيص داد و اثر اقدامهاى زراعى و تنشهاى مختلف را بر عملكرد يك زيستبوم برآورد نمود و در نهايت از اين اطلاعات در راستاى مديريت شبكهاى غذايى خاك بهره جست.

\section{References}

1. Angst S, Mueller CW, Cajtham T, Angst G, Lhotáková Z, Bartuška M, Špaldoňová A, Frouz J (2017) Stabilization of soil organic matter by earthworms is connected with physical protection rather than with chemical changes of organic matter. Geoderma 289:29-35.

2. Bongers T, Bongers M (1998) Functional diversity of nematodes. Applied Soil Ecology 10:239-251

3. Bongers T, Ferris H (1999) Nematode community structure as a bioindicator in environmental monitoring. Trends in Ecology and Evolution 14:224-228.

4. Bongers T (1990) The maturity index: an ecological measure of environmental disturbance based on nematode species composition. Oecologia 83:14-19.

5. Ferris H, Bongers T (2009) Indices Developed Specifically for Analysis of Nematode Assemblages. Pp. 124-145. In: MJ Wilson, T Kakouli-Duarte (Eds.). Nematodes as Environmental Indicators. CABI Publishing, England. 
6. Ferris H (2010) Form and function: metabolic footprints of nematodes in the soil food web. European Journal of Soil Biology 46:97-104.

7. Ferris H (2012) Nematodes as Bio indicators. Pp. 677-698. In: RH Manzanilla-López, N Marbán-Mendoza (Eds.). Practical Plant Nematology. Biblioteca Básica de Agricultura Publication, Mexico.

8. Ferris H, Bongers T, de Goede RGM (2001) A framework for soil food web diagnostics: extension of the nematode faunal analysis concept. Applied Soil Ecology 18:13-29.

9. Ferris H, Bongers, T, de Goede RGM (2004) Nematode Faunal Analyses to Assess Food Web Enrichment and Connectance. Pp.503-510. In: RC Cook, DJ Hunt (Eds.). Proceedings of the Fourth International Congress of Nematology, Tenerije, Spain, 813 June 2002, Nematology Monographs and Perspectives, Volume 2. Leiden, The Netherlands, Brill.

10. Hodda, M., Peters, L. and Traunspurger, W. (2009) Nematode Diversity in Terrestrial, Freshwater Aquatic and Marine Systems. Pp. 45-93. In: MJ Wilson, T Kakouli-Duarte (eds.). Nematodes as Environmental Indicators. CABI Publishing, England.

11. Karr JR (1981) Assessment of Biotic Integrity Using fish Communities. Fisheries 6:21-27.

12. Ma Q, Yu H, Liu X, Xu Z, Zhou G, Shi Y (2018) Climatic warming shifts the soil nematode community in a desert steppe. Climatic Change 150:243-258.

13. McSorley R, Wang KH, Church G (2008) Suppression of root-knot nematodes in natural and agricultural soils. Applied Soil Ecology 39:291-298.

14. Navas A, Flores-Romero P, Sánchez-Moreno S, Camargo JA, McGawley EC (2010) Effects of heavy metal soil pollution on nematode communities after the Aznalcóllar mining spill. Nematropica 40:13-30.

15. Neher DA, Darby BJ (2009) General Community Indices that can be used for Analysis of Nematode Assemblages. Pp.107-123. In: MJ Wilson, T Kakouli-Duarte (Eds.). Nematodes as Environmental Indicators. CABI Publishing, England.

16. Neher DA (2001) Role of nematodes in soil health and their use as indicators. Journal of Nematology 33:161.

17. Ruess L, Ferris H (2004) Decomposition Pathways and Successional Changes. Pp. 547-556. In: R Cook, DJ Hunt (Eds.). Proceedings of the Fourth International Congress of Nematology, Tenerije, Spain, 8-13 June 2002, Nematology Monographs and Perspectives, Volume 2. Leiden, The Netherlands, Brill.

18. Sánchez-Moreno S, Navas A (2007) Nematode diversity and food web condition in heavy metal polluted soils in a river basin in southern Spain. European Journal of Soil Biology 43:166-179.

19. Sieriebriennikov B, Ferris H, de Goede RGM (2014) NINJA: An automated calculation system for nematode-based biological monitoring. European Journal of Soil Biology 61:90-93. 
20. Sohlenius B (1990) Influence of cropping system and nitrogen input on soil fauna and microorganisms in a Swedish arable soil. Biology and Fertility of Soils 9:168-173.

21. Tolfa I, Velki M, Vukovic R, Ecimovic S, Katanic Z, Loncaric Z (2017) Effect of different forms of selenium on the plant-soil-earthworm system. Journal of Plant Nutrition and Soil Science 180:1-10.

22. Trett MW, Urbano BC, Forster SJ, Trett SP (2009) Commercial aspects of the use of nematodes as bioindicators. pp. 275-314. In: MJ Wilson, T Kakouli-Duarte (Eds.). Nematodes as Environmental Indicators. CABI Publishing,

23. Van den Hoogen J, Geisen S, Routh D, Ferris H, Traunspurger W, Wardle DA, Bardgett RD, Crowther TW (2019) Soil nematode abundance and functional group composition at a global scale. Nature 572:194-198.

24. Yeates GW (1997) Soil nematodes as indicators of the effect of management on grasslands in the New England Tablelands (NSW): comparison of native and improved grasslands. Pedobiologia 41:526-536.

25. Yeates GW, Bongers TD, de Goede, RGM, Freckman DW, Georgieva SS (1993) Feeding habits in soil nematode families and genera an outline for soil ecologists. Journal of Nematology 25:315-331.

26. Yeates GW, Ferris H, Moens T, Van der Putten WH (2009) The role of nematodes in ecosystems. pp.1-44. In: MJ Wilson, T Kakouli-Duarte (eds.). Nematodes as Environmental Indicators. CABI Publishing, England.

27. Zhang ZW, Li Q, Zhang HY, Hu YY, Hou SL, Wei HW, Lü XT (2019) The impacts of nutrient addition and livestock exclosure on the soil nematode community in a degraded grassland. Land Degradation and Development 30:1574-1583. 